\title{
É possível filosofar com Heidegger após as confissões nos Cadernos Pretos? ${ }^{1}$
}

\author{
Is it possible to philosophize with Heidegger \\ after the confessions in Cadernos Pretos?
}

LUIZ ROHDEN (iDa

MARCOS ANDRÉ WeBber (Db

\section{Resumo}

Neste artigo proporemos uma resposta à pergunta se é possível filosofar com Heidegger após as confissões nos Cadernos Pretos relativas ao seu comprometimento, parcial, com o nazismo e o antissemitismo. Para além da alternativa que aborda a obra de Heidegger, ignorando ou minimizando seu compromisso político, ou daquela que a descarta em razão do seu vínculo com nazismo, justificaremos que sua proposta filosófica é válida e profícua, mesmo

\footnotetext{
${ }^{1}$ Este artigo contou com apoio da CAPES, da FAPERGS - PQg 2017 e do CNPq Edital Universal 2018. Registramos nosso agradecimento ao colega Prof. Dr. Álvaro Valls pela leitura deste artigo bem como pelas sugestões relativas ao estilo e aos argumentos desenvolvidos.

a Universidade do Vale do Rio dos Sinos (UNISINOS), São Leopoldo, RS, Brasil. Doutor em Filosofia, e-mail: rohden@unisinos.br

b Universidade do Vale do Rio dos Sinos (UNISINOS), São Leopoldo, RS, Brasil. Doutor em Filosofia, e-mail: marcoswebber@terra.com.br
} 
após a publicação dos Cadernos Pretos. Sob a égide da hermenêutica gadameriana, inicialmente apresentaremos a posição de Heidegger por ele descrita nos Cadernos Pretos; a seguir, explicitaremos alguns aspectos do antissemitismo heideggeriano em relação ao partido nacional-socialista; para, ao final, fundamentarmos que a proposta filosófica de Heidegger, veiculada em sua obra, não deveria ser descartada em razão do seu equívoco político, uma vez que o texto escrito passa a ter vida própria e se torna independente do seu criador, cabendo aos leitores interpretá-lo de forma crítica, honesta e responsável.

Palavras-chave: Heidegger. Cadernos Pretos. Gadamer. Hermenêutica filosófica. Diálogo.

\begin{abstract}
In this article we propose an answer to the question whether it is possible to philosophize with Heidegger after the confessions he made in the Black Notebooks about his partial commitment to Nazism and anti-Semitism. Going beyond the alternative of approaching Heidegger's work by ignoring or minimizing his political commitment or by dismissing it altogether because of his connection with Nazism, we claim that his philosophical proposal is valid and fruitful even after the publication of the Black Notebooks. Under the aegis of Gadamer's interpretation, initially we present Heidegger's position as described by himself in the Black Notebooks; we then discuss some aspects of Heidegger's anti-Semitism in relation to the Nazi Party; finally, we justify that he philosophical proposal articulated in Heidegger's work should not be dismissed because of his political mistake, since the written text acquires a life of its own and becomes independent from its creator, so that it is up to the readers to interpret it in a critical, honest and responsible manner.
\end{abstract}

Keywords: Heidegger. Black Notebooks. Philosophical hermeneutics. Gadamer. Dialog.

\title{
Estado da questão: Heidegger, Filosofia e o Nazismo
}

Considerando que o filosofar estriba-se sobre o esforço de olhar o todo, faz parte do mister filosófico abrir-se e posicionar-se diante de todos aqueles problemas difíceis e doloridos. No caso, voltamo-nos aqui sobre o comprometimento de Heidegger com o nazismo e o antissemitismo, o que significa mexer com uma ferida aberta no corpo acadêmico filosófico.

São duas as justificativas para nos ocuparmos desse delicado e indigesto problema: a) do ponto de vista teórico, almejamos ampliar o horizonte de compreensão acerca do compromisso de Heidegger com o nazismo e o 
antissemitismo; b) com o escopo de fundamentar uma terceira via de abordagem em relação à obra, para além da alternativa que ignora essa mácula heideggeriana ou daquela que a descarta por causa dela. Visamos pavimentar uma proposta alternativa, via hermenêutica gadameriana, lançando luzes e fundamentando que o erro, ou equívoco, político de Heidegger não invalida, nem tira a força da sua obra, embora tire parte de seu brilho.

Alertamos nosso leitor que não compactuamos, de forma alguma, com propostas teóricas, nem com posturas que não acolhem, que não respeitam, que não cuidam, e que não tratam o outro como fim em si mesmo. Partimos do pressuposto segundo o qual o filosofar consiste, em sua essência, em dialogar com os textos, com fatos, com as pessoas, a fim de instituir o sentido ou um ethos mais harmônico possível e solidário, pautado pelo respeito, pela liberdade e mútua responsabilidade, em contraponto à xenofobia, ao racismo, ao sexismo, ao totalitarismo.

Desenvolveremos nossa reflexão sobre três pilares: descreveremos a posição de Heidegger com relação ao nazismo escrita por ele nos Cadernos Pretos; a seguir, caracterizaremos o antissemitismo de Heidegger em relação ao partido nacionalsocialista alemão; ao final elaboraremos nossa posição crítica sobre esse problema à luz da nossa compreensão de filosofia hermenêutica.

\section{Heidegger e o nazismo: os Cadernos Pretos no âmbito da Gesamtausgabe}

A adesão de Heidegger ao partido nacional-socialista e ao antissemitismo que aparece em alguns de seus discursos, especialmente nos anos 1930, não é um tema recente. Desde os anos 1980, inúmeras são as publicações que abordam o assunto, lançando críticas e buscando compreender a relação de Heidegger com os judeus na Alemanha de sua época.

Com o surgimento de novos documentos e escritos políticos, dentre os quais se destaca a publicação dos chamados Cadernos Pretos, abriu-se um novo capítulo na discussão. Se, por um lado, Heidegger foi acusado de silenciar sempre que questionado sobre o seu envolvimento com o partido nazista, os Cadernos Pretos, por 
sua vez, trazem de forma muito clara, não apenas o seu grau de comprometimento com o partido nacional-socialista, mas a dimensão política do seu pensamento. Se, por um lado, estes documentos mais recentes revelam a rejeição de Heidegger à ideologia de opressão biológica e racial característica do movimento nacionalsocialista, por outro torna-se inegável que Heidegger defendia o antissemitismo.

Trata-se, sem dúvida, de um tema difícil, uma vez que suas consequências não ficam restritas apenas a Heidegger — seja o homem ou a sua filosofia. Se levarmos em consideração que concepções antissemitas — especialmente a partir dos anos 1930 podem ter contaminado a filosofia de um dos pensadores mais influentes do século $\mathrm{XX}$, a questão atinge a filosofia como um todo. Como foi possível que um dos filósofos mais importantes do século XX tenha sido favorável não apenas ao nacionalsocialismo, mas também ao antissemitismo, é uma questão que transcende à mera interpretação da filosofia heideggeriana, na medida em exige que se leve em consideração o contexto social, político e cultural da Alemanha da época.

Assim denominados pelo próprio Heidegger, em razão da cor das suas capas, os Cadernos Pretos são constituídos por 34 cadernos de capa preta encerada, organizados do seguinte modo: quatorze cadernos com o título Consideracõos (Überlegungen), nove como Notas (Anmerkungen), dois como Quatro Cadernos (Vier Hefte), dois como Vigiliae, um como Notturno, dois como Indicações (Winke), e quatro como Ínterins (Vorläufiges). $\mathrm{Na}$ grande maioria são títulos simples, compostos por uma série de anotações que compreendem um extenso período, entre 1931 e 1976. Nos últimos anos, dois outros cadernos surgiram, denominados Megiston e Grundworte, mas não há previsão de que estes volumes venham a ser publicados como parte da Gesamtausgabe (ESCUDERO, 2015, p. 24).

A primeira série de cadernos, composta por 3 volumes, escritos entre os anos de 1931 e 1941, e publicados em 2014 (GA 94-96), traz um novo estilo de escrita ao longo de mais de 1.200 páginas. Em geral, são anotações e reflexões sobre o curso que a sua filosofia tomou após Ser e Tempo, além de esclarecimentos sobre o seu segundo trabalho fundamental, Contribuições à Filosofia (GA 65), obedecendo a um estilo peculiar, que poderia ser denominado “diário de pensamento" (Denktagebuch) (ESCUDERO, 2015, p. 25). Ocorre, porém, que, no bojo dessas anotações, encontram-se uma série de reflexões acerca da crescente mecanização da vida 
cotidiana, opiniões sobre o nacional-socialismo e sobre o judaísmo. Em março de 2015, os cadernos denominados Anmerkungen I-V (Schwarze Hefte 1942-1948) foram publicados como volume 97 da Gesamtausgabe.

A reação da comunidade filosófica como um todo foi de choque e repulsa frente à gravidade e à clareza de algumas das afirmações. O que até então ainda era colocado em dúvida, visto que raros foram os momentos em que Heidegger se manifestou sobre sua adesão ao partido nacional-socialista, revelou-se uma certeza indefensável. Inúmeras são as questões que emergem dessa situação, que podem ser reunidas no problema que fizemos objeto de nossa reflexão aqui, a saber, afinal, como ler Heidegger após a publicação do volume 97, se é que ainda devemos lê-lo?

Poderíamos, em um primeiro momento, nos perguntar se não seria correto abandonarmos Heidegger e o rejeitarmos por sustentar um pensamento marcado pela ideologia antissemita. No entanto, será que esta seria uma atitude filosoficamente adequada, antes mesmo de termos ciência, tanto da extensão do comprometimento de Heidegger com o partido nacional-socialista, quanto do tipo de antissemitismo que marcou o posicionamento político do filósofo alemão? Será que o abandono a Heidegger significaria fazer justiça à própria filosofia, colocando os escritos políticos de um pensador acima de qualquer contribuição que ele possa ter trazido à história da filosofia?

Ocorre que, na medida em que o pensamento heideggeriano exerceu influência decisiva em diversas figuras importantes do pensamento do século $\mathrm{XX}$, o simples abandono da filosofia de Heidegger configuraria uma simplificação demasiada da questão. Na França, por exemplo, é inegável a influência da filosofia de Heidegger em pensadores como Jean-Paul Sartre, Jacques Derrida e Paul Ricoeur; na Alemanha, em Hans-Georg Gadamer e Jürgen Habermas; dentre os alemães que desenvolveram seus trabalhos nos Estados Unidos, Herbert Marcuse, Leo Strauss e Paul Tillich; além da Hannah Arendt, que foi uma das maiores defensoras da reputação de Heidegger nos países de língua inglesa após a Segunda Guerra Mundial. Por décadas, o alcance das obras heideggerianas ultrapassou e continua transpassando as fronteiras da Europa e dos Estados Unidos, sendo atualmente lido no Japão, China, América Latina e até mesmo no Irã (FRIED, 2016, p. 45). Se devêssemos abandonar a filosofia de 
Heidegger, deveríamos então abandonar também o pensamento de todos aqueles influenciados pelos textos heideggerianos? Nós defendemos que não, uma vez que tal postura caracterizaria uma fuga do enfrentamento filosófico solicitada pela questão e que fizemos nosso objeto de reflexão aqui.

Ao publicar um importante livro para o debate sobre possíveis implicações éticas da filosofia heideggeriana, muito antes da publicação dos Cadernos, Hatab dedicou um pequeno capítulo a uma reflexão acerca da relação de Heidegger com o nacional-socialismo. Nele Hatab (2000, p. 201) lança duas importantes questões referindo-se à posição política de Heidegger: "Primeiro, a sua visão do nacionalsocialismo coincidiu com a visão do regime de Adolf Hitler? Segundo, foi o seu comprometimento com o fascismo uma consequência necessária da sua filosofia?”. A resposta de Hatab às duas questões é “não", acrescentando que, mesmo se não pudermos separar o homem Heidegger do nazismo, sua filosofia abriga uma rica fonte de possibilidades, que não se limitam à ideologia nazista. Até porque existem elementos em sua visão política que não se mostram consistentes com a sua filosofia.

$\mathrm{Na}$ esteira da análise de Hatab, se faz necessário levantarmos novos questionamentos, que se legitimam em razão das possíveis implicações do antissemitismo na obra heideggeriana como um todo. Afinal, qual a extensão da influência do antissemitismo de Heidegger na sua filosofia?; em que medida as sentenças antissemitas representam um compromisso filosófico de Heidegger com aspectos centrais da ideologia nacional-socialista?; por que Heidegger não omitiu os Cadernos Pretos da Gesamtausgabe, fazendo questão de publicá-los como encerramento das suas obras completas?; é possível separar de forma tão clara o filósofo do seu pensamento?; dado o seu comprometimento com o nazismo, é possível falar de ética a partir do pensamento heideggeriano? Essas e outras questões se impõem como desafios, cujas respostas podem colocar em jogo a filosofia de um dos maiores expoentes do pensamento do século XX.

Em entrevista concedida em 2015 sobre o tema, Günter Figal revelou que o antissemitismo de Heidegger exposto nos Cadernos Pretos foi a principal razão para a sua renúncia ao cargo de presidente da Sociedade Heidegger Alemã. Figal recusa-se, no entanto, a caracterizar Heidegger como um "pensador fascista"; além disso, 
reconhece que Gadamer, Arendt, Löwith, Sartre, Merleau-Ponty, Levinas, Derrida, Foucault, entre outros, foram influenciados por Heidegger e que suas concepções filosóficas não constituem nem fundamentam uma perspectiva fascista. Embora os Cadernos Pretos nos apresentem uma estranha mistura de filosofia e ideologia, é preciso encarar os dois lados de Heidegger — o filosófico e o ideológico —, para então discutirmos em que grau o seu pensamento filosófico pode ser compreendido sem referir-se a pressupostos ideológicos, e em que medida sua dimensão ideológica poderá ou não ter influenciado outros pensadores (RALON, 2015).

Assim, Figal nos coloca outra difícil questão. Se considerarmos a filosofia heideggeriana como uma filosofia fascista em sua essência, e que este caráter fascista é motivo suficiente para que seja abandonada, o mesmo deve ocorrer como todos aqueles filósofos por ela influenciados. Afinal, se a filosofia heideggeriana como um todo deve ser caracterizada como produto de uma ideologia fascista, o pensamento de todos aqueles influenciados por tal filosofia estaria também contaminado pelas convicções ideológicas fascistas. A este respeito, nos alinhamos com Figal e Hatab, recusando-nos a caracterizar Heidegger como um "pensador fascista". Do mesmo modo, entendemos que o antissemitismo manifestado por Heidegger, especialmente nos Cadernos, não é uma consequência direta da dimensão estritamente filosófica do seu pensamento, mas fruto de convicções ideológicas de sua época. Conforme o próprio Figal indica, o desafio para as pesquisas que tratem do pensamento heideggeriano nos próximos anos exige separar o conteúdo ideológico do pensamento puramente filosófico. No fundo, a questão que se coloca é: como interpretar o pensamento de Heidegger após a publicação dos Cadernos Pretos e qual a contribuição que Heidegger pode dar à filosofia, apesar da sua mácula antissemita?

\section{Heidegger, antissemita, mas não um nazista em sua essência?}

Caracterizaremos aqui o antissemitismo de Heidegger relativo ao partido nacional-socialista alemão. $\mathrm{Na}$ medida em que as duas conotações do pensamento de Heidegger devem ser levadas em conta — a filosófica e a ideológica, ou sua 
obra/texto escrito e seu compromisso/posicionamento ideológico —, torna-se fundamental colocar em discussão o grau em que seu pensamento filosófico estaria comprometido com pressupostos ideológicos. As duas posições extremistas aquela que ignora o compromisso de Heidegger com o nazismo e o antissemitismo e a que descarta a filosofia heideggeriana em razão de tal compromisso — podem provocar uma simplificação demasiada do tema. Se, por um lado, atribuir apressadamente uma carga ideológica ao seu pensamento como um todo pode levar-nos a fugir de um verdadeiro enfrentamento da questão, por outro, ignorar que Heidegger aderiu ao partido nazista e que compartilhava de um certo tipo de sentimento antissemita, significa retirar do contexto histórico no qual a filosofia heideggeriana se insere, provocando uma interpretação equivocada do seu pensamento como um todo.

Mostra-se curioso que Heidegger, ao mesmo tempo em que manifestou um sentimento antissemita, cultivou com alguns judeus uma relação amigável, cortês e até íntima. Por um lado, não podemos esquecer que Heidegger, na qualidade de reitor da Universidade de Freiburg, afastou o seu mestre Husserl, dentre outros judeus, do quadro de professores da universidade, em cumprimento à lei de reorganização dos quadros de funcionários, decretada em 7 de abril de 1933, a qual excluía do serviço público todos os "não-arianos". Esta foi, para Husserl, a "maior ofensa" de sua vida, sentindo-se traído, sobretudo em seu sentimento nacional. Mas por outro lado, também devemos lembrar que o mesmo Heidegger intercedeu junto ao Ministério da Cultura em favor de Eduard Fraenkel e Georg von Hevesey, professores que estavam por ser demitidos como judeus, argumentando que eram judeus distintos de caráter exemplar (SAFRANSKI, 2005, p. 303-304).

No entanto, como observa Trawny (2015, p. 96-97), editor dos Cadernos Pretos na Gesamtausgabe, nenhum desses relacionamentos foi interrompido por motivos antissemitas. Muito pelo contrário, muitos deles sobreviveram à própria Shoah ou foram depois dela iniciados. A esse respeito, os Cadernos evidenciam de forma ainda mais acentuada a ambiguidade que caracterizou a relação de Heidegger com os judeus. Ao mesmo tempo que manteve relações bastante próximas — senão íntimas — não apenas com o seu mestre Husserl, mas com inúmeros alunos e colegas, 
Heidegger compartilhou do desprezo generalizado do preconceito antissemita que marcou a Alemanha da época.

\subsection{Heidegger, nazista, em parte!}

A relação, de certo modo paradoxal, com os judeus foi possível justamente porque o antissemitismo externado por Heidegger não era o mesmo antissemitismo que marcou o nacional-socialismo ${ }^{2}$, o que ficou evidenciado com a publicação dos Cadernos. Este, sem dúvida, é um ponto central na análise que devemos fazer do antissemitismo heideggeriano e do julgamento que fazemos de Heidegger enquanto ser humano. Que Heidegger era nazista, e que ele carregava sentimentos antissemitas, são fatos que se mostram inegáveis. Enquanto fatos, realmente são muito simples. Mas a verdadeira questão diz respeito ao significado de tais fatos e de como eles deveriam ser interpretados (MALPAS, 2016, p. 5-6). Ocorre que, independentemente dos termos que se pretenda utilizar — nazismo ou antissemitismo —, nenhum deles possui um significado unívoco ou evidente. Seu significado é sempre dependente do momento histórico em que ele se dá. Por isso não podemos assumir que o modo como os termos "nazismo" ou "antissemitismo" são compreendidos hoje é idêntico ao sentido que tais termos possuíam na Alemanha nas décadas de 1930 e 1940.

Ademais, o antissemitismo manifestado nas Considerações parece estar fundamentalmente baseado em uma forma de antissemitismo cultural que se espalhou não apenas pela Alemanha, mas pela Europa, antes da Segunda Guerra Mundial, e que não desapareceu logo em seguida, mesmo após o Holocausto (MALPAS, 2016, p. 6). Isso se deve ao fato de que o tipo de antissemitismo que permaneceu, mesmo no pós-guerra, estava baseado em diferenças culturais, muito

\footnotetext{
2 Trawny (2015, p. 21-22) ressalta que Heidegger escondeu este fato até mesmo dos nacional-socialistas: "As declarações antissemitas de Heidegger - inscritas em um contexto filosófico - se encontram exclusivamente nos manuscritos que o filósofo quis manter, o tanto quanto possível, longe da esfera pública. Ele ocultou seu próprio antissemitismo até dos nacional-socialistas".
} 
mais do que em diferenças naturais, o que não implica que formas culturais de antissemitismo não pudessem se transformar em formas naturalizadas.

Evidentemente que não se quer aqui defender ou justificar o antissemitismo desprezível que se manifesta nos escritos heideggerianos. O que se busca é tentar compreender o antissemitismo de Heidegger, e situá-lo, tanto historicamente quanto em relação à sua obra. $\mathrm{Na}$ medida em que os Cadernos evidenciam que o antissemitismo heideggeriano não é o mesmo antissemitismo do nacionalsocialismo, talvez o primeiro desafio seja justamente o de compreender o tipo de antissemitismo que marcou a vida e o pensamento político de Heidegger. Até porque a existência de um sentimento antissemita entre os filósofos alemães de forma alguma foi uma exclusividade de Heidegger, tendo sido observado também em anotações pessoais de outros pensadores ${ }^{3}$.

A este respeito, destaca Duarte (2015, p. 46) que um dos aspectos mais relevantes em relação às teses preconceituosas de Heidegger sobre os judeus é que elas foram formuladas em chave filosófica. A dificuldade se encontra justamente em determinar se tais preconceitos possuem origem na ideologia nazista, embora Heidegger claramente recusou, por motivos filosóficos, o caráter biológico-racial, ou se eles teriam um fundo meramente religioso, cultural, espiritual e social. O problema reside no fato de que inúmeros preconceitos, sejam eles culturais, sociais ou religiosos, teriam sido incorporados à ideologia nazista, tornando a distinção entre ambos uma tarefa de difícil execução.

É preciso notar, contudo, que a reflexão acerca das consequências de uma possível influência do antissemitismo na filosofia de Heidegger não se coloca como uma questão exclusivamente entre os ditos "heideggerianos". Prova disso é o recente embate entre Emmanuel Faye, autor do livro publicado em 2005, intitulado Heidegger: a introdução do nazismo na filosofia, e Thomas Sheehan que, em resposta à interpretação que Faye faz do antissemitismo heideggeriano, publica em 2015 um artigo intitulado Emmanuel Faye: a introducão da fraude na filosofia. Ao passo que Faye (2015, p. 48) acusa Heidegger de conspirar para a introdução do nazismo na

\footnotetext{
${ }^{3}$ Malpas (2016, p. 20) lembra o choque descrito por Michael Dummett, ao ler pela primeira vez um fragmento de um diário de Gottlob Frege que nunca fora publicado, em que este demonstra ter sido, ao menos no final de sua vida, um virulento racista e antissemita.
} 
filosofia, através da produção de textos que, "na medida em que fazem a apologia de uma discriminação assassina, constituem a negação mais radical das verdades humanas que estão no princípio da filosofia", Sheehan acusa Faye de ter mal traduzido e mal interpretado as obras heideggerianas, retirando frases do seu contexto, chegando até mesmo a reescrever alguns textos. A forma áspera como os debates têm ocorrido evidenciam se tratar de uma ferida não apenas na biografia de Martin Heidegger, mas na história da filosofia como um todo.

Em abril de 1933, Heidegger aceita o cargo de reitor da Universidade de Freiburg, já sob o novo regime nazista, proferindo o seu discurso de posse em 27 de maio de 1933. Durante o período em que permaneceu no cargo de reitor, Heidegger fez cumprir as leis anti-judeus, afastando professores, funcionários e alunos, e proferiu discursos em favor de Hitler, mostrando sua adesão e apoio ao partido nazista. Observa Farin (2016, p. 298), contudo, que o pessimismo de Heidegger em relação ao nacional-socialismo cresceu nos meses que se sucederam ao seu discurso de posse da reitoria. A sua insatisfação com a realidade do nacional-socialismo é justamente o que provocaria a sua renúncia à reitoria, ocorrida abruptamente em 28 de abril de 1934.

\subsection{Sobre o antissemitismo de Heidegger}

Talvez o primeiro passo para tentarmos compreender o antissemitismo heideggeriano seja justamente observarmos a forma como ele se manifesta em seus apontamentos. Trawny faz referência a três importantes passagens, em que podemos perceber o modo como antissemitismo de Heidegger aparece nos Cadernos Pretos.

$\mathrm{Na}$ primeira dessas passagens, o judeu aparece como dominado pela "maquinação" (Maschenchaft), como um sujeito calculador, desprovido de mundo. Por maquinação, Heidegger compreende a racionalização e tecnicização totalizante do mundo, associando o elemento calculador com a visão de mundo estritamente judia (ESCUDERO, 2015, p. 25-26). Escreve Heidegger: 
A escalada momentânea do Judaísmo tem, porém, seu fundamento no fato de a metafísica do Ocidente, especialmente em seu desdobramento moderno, ser o ponto de ancoragem para o alargamento de uma racionalidade vazia e uma aptidão para o cálculo que desse modo ganham morada no "espírito", sem jamais alcançar sua própria região oculta de decisão. Quanto mais originárias e principais as futuras decisões e questões, mais inacessíveis elas permanecem para essa "raça". (Assim, o passo de Husserl para a consideração fenomenológica, que se distancia tanto da explicação psicológica quanto da apreensão histórica das opiniões, possui uma importância duradoura - mesmo assim, nunca alcança a região de decisões essenciais, pressupondo bem mais a tradição histórica da filosofia por toda parte; a consequência necessária se mostra imediatamente quando encontra a filosofia transcendental kantiana, que por fim é um avanço inevitável em direção ao hegelianismo em sentido formal. Meu "ataque" contra Husserl se dirige somente contra ele e não tem relevância - o ataque é contra a omissão da pergunta pelo Ser, ou seja, contra a essência da metafísica como tal, em razão da qual a maquinação dos entes consegue determinar a história. O ataque funda uma perspectiva historial da mais alta decisão entre a primazia dos entes e a fundação da verdade de Ser) (HEIDEGGER, 2014c, p. 37-38).

$\mathrm{Na}$ segunda passagem, Heidegger expressa um antissemitismo que é designado por Trawny (2015, p. 50) como "racial" ou "racista". Muito embora Heidegger negue expressamente o pensamento de raça, ele presume um sentido especial de raça no ser-lançado e, dessa forma, na historicidade. Observemos:

Por meio de um talento calculador acentuado, os judeus "vivem" de há muito sob o princípio de raça, razão pela qual resistem veementemente contra a sua aplicação irrestrita. A instituição da cria racial não tem origem na própria "vida", mas sim na subjugação da vida pela maquinação. O que se opera com esse planejamento é a desracialização total dos povos através de ser próprio assujeitamento à instituição e recorte uniformizado e unidimensional dos entes. Com a desracialização, um autoestranhamento dos povos - a perda da história ou seja, o âmbito de decisão de Seer vira um só (HEIDEGGER, 2014c, p. 38).

A este respeito, podemos perceber um ponto central da distinção entre o antissemitismo encontrado nos textos heideggerianos e o antissemitismo do partido nacional-socialista. Se, por um lado, Heidegger aceita e reconhece que há algo como uma "raça" como parte da facticidade e enquanto condição da existência histórica, por outro lado, o filósofo alemão rejeita veemente a noção de raça como fator incondicional ou absoluto. Ao passo que o antissemitismo de Hitler é brutalmente biológico, os Cadernos vêm demonstrar que Heidegger rejeitou o biologismo da ideologia nazi e sua retórica racista. Seu interesse maior estava voltado às considerações filosóficas de alguns problemas fundamentais do nacional-socialismo, particularmente da questão do que significa ser um povo (Volk). Nesse sentido, um povo não pode ser pensado em termos raciais ou biológicos, mas com o espírito da nação, que nada mais é do que o modo de ser de um povo (ESCUDERO, 2015, p. 29). 
$\mathrm{Na}$ interpretação de Trawny, Heidegger se posicionou contra o "pensamento de raça" do nacional-socialismo, interpretando-a como consequência da maquinação. Nas Considerações XII, encontramos a afirmação de que "todo pensamento de raça" é "moderno", movimenta-se "na linha de apreensão do homem como sujeito" (HEIDEGGER, 2014c, p. 48). Heidegger pensa que a "instituição da cria racial" não se origina "da própria vida", na medida em que a "vida" acontece sem se alinhar à formação e ao aprimoramento da raça. Há inegavelmente um afastamento da noção de "raça" enquanto questão biológica, sob o argumento de que "o lidar cotidiano do homem não se ocupa da 'manutenção da pureza' de uma 'raça"” (TRAWNY, 2015, p. 46). Torna-se necessária uma "instituição" — ou seja, uma "maquinação" —, para que a "vida" se organize desse modo. Esta organização é justamente o que Heidegger identifica nos nacionalsocialistas (TRAWNY, 2015, p. 46).

Ademais, observa Duarte que não encontramos nos Cadernos Pretos qualquer afirmação na qual Heidegger defenda o extermínio do povo judeu, o que evidencia que seu antissemitismo, sob o ponto de vista filosófico, nada tem que ver com genocídio ou com concepções raciais de natureza estritamente biológica. Quando Heidegger se refere ao povo judeu em termos de "raça", ele frequentemente faz uso de aspas,

\begin{abstract}
dando assim a entender que seu conceito filosófico-historial de raça, a despeito de indeterminado, não se confundiria com o conceito racial biológico do nacional-socialismo, de modo que o filósofo tampouco se comprometeria com as consequências políticas desta noção, isto é, o extermínio de uma raça considerada inferior e perigosa (DUARTE, 2015, p. 47).
\end{abstract}

Em um terceiro momento, Heidegger faz referência ao Judaísmo mundial como um elemento metafísico com um papel especial enquanto ativo representante internacional da técnica. Os judeus seriam um povo desprovido de enraizamento em uma terra-natal própria, dispersos pelo mundo, formando uma comunidade mundial capaz de agir em todos os países, de maneira livre e desvinculada, acirrando a perda de raízes de todos os povos. Nesse sentido, o judaísmo mundial constituiria um princípio metafísico de destruição (DUARTE, 2015, p. 41). 
Também a ideia de um entendimento com a Inglaterra, no sentido de compartilhar as "prerrogativas" do imperialismo, não alcança o processo historial em sua essência, pois a Inglaterra, agora no âmbito do Americanismo e do Bolchevismo, por sua vez, também no âmbito do Judaísmo mundial, participa do jogo até o fim. A pergunta pelo papel do Judaísmo mundial não é racial, mas sim uma pergunta metafísica pelo modo de ser do tipo de serhomem, que completamente desarraigado pode assumir o desenraizamento de todos os entes de Ser, enquanto "tarefa" histórica mundial (HEIDEGGER, 2014c, p. 243).

Sob a perspectiva estritamente filosófica, Trawny (2015, p. 67) sustenta que seja provável que Heidegger jamais, ou apenas em um âmbito muito restrito, tenha concordado com o nacional-socialismo existente. Se julgarmos apenas pelos Cadernos, o entusiasmo de Heidegger pelo nacional-socialismo se estendeu por um período muito curto de tempo. Imediatamente após a sua renúncia à reitoria, ocorrida em abril de 1934, diversos aspectos do nacional-socialismo passam a ser criticados por Heidegger, dentre os quais se destacam a "idolatria do povo" (Vergötzung des Volkes) (HEIDEGGER, 2014a, p. 223), e a "idolatria da raça" (Vergötzung der Rasse) (HEIDEGGER, 2014a, p. 261).

Heidegger não acredita que "um povo" seja sempre um fim em si mesmo, nem concorda com a ideia de que tudo deva ser mensurado com base em um suposto ganho para “o povo". Daí por que Heidegger condena tais atitudes do nacional-socialismo, considerando que a invocação ritualística da "comunidade" (Gemeinschaft) é uma grande mentira, resultado do roubo e exploração espiritual e material do "povo" pelo suserano. Em Considerações IV, Heidegger (2014a, p. 221) pergunta por quanto tempo deve este roubo continuar.

Desse modo, ao mesmo tempo em que reafirmam a adesão de Heidegger ao nacional-socialismo, os próprios Cadernos também evidenciam a dissidência da filosofia heideggeriana frente a diversos aspectos da ideologia nazi. Heidegger (2014b, p. 408) justifica que o seu apoio ao nacional-socialismo no período de 1930 a 1934 — antes, portanto, do que muitos imaginavam — se deu em razão de ter vislumbrado no movimento a possibilidade filosófica de transição para um novo início, no espírito do seu pensamento da história do ser. O primeiro início da filosofia teria ocorrido com os gregos, mas teria chegado ao fim, na visão de mundo tecnológica, resultado do esquecimento do ser. Caberia, assim, ao povo alemão estabelecer um novo início, na medida em que somente um novo início poderia nos salvar. Foram justamente sinais da 
possibilidade de um novo início que Heidegger afirma ter percebido no nacionalsocialismo, que desta vez poderia ocorrer sobre fundamentos filosóficos.

A verdade é que a leitura dos Cadernos Pretos está apenas começando. Conclusões apressadas acerca das implicações dos Cadernos para uma nova interpretação da obra heideggeriana como um todo podem se mostrar equivocadas nos anos que estão por vir. Não se trata de um problema a ser abordado apenas pelos que se autodenominam "heideggerianos", mas para a comunidade acadêmica. O desafio está lançado. O caminho para depurar a Gesamtausgabe, para dela retirar tudo o que estiver contaminado pelo antissemitismo, e assim podermos compreender o pensamento de Heidegger sob a perspectiva puramente filosófica, não se mostra ainda claro. Um distanciamento crítico se faz necessário, como uma tarefa lançada à comunidade filosófica.

\section{Por que ainda filosofar com Heidegger, apesar do seu erro político?}

Antes de tecermos nossa terceira via, para além da adesão cega ou da rejeição rasteira de Heidegger, ressaltamos que não compactuamos, nem com seu comprometimento com o nazismo, nem com sua convicção antissemita. Inicialmente, responderemos à pergunta acima com um argumento de ordem mais pessoal, relativo à postura de Gadamer para com Heidegger e sua obra; a seguir, desenvolveremos razões que justificam a apropriação de sua obra.

\subsection{Apropriação crítica da obra de Heidegger a partir de Gadamer}

É fato que "as posições políticas opostas entre Heidegger e seu aluno Gadamer, no ano de 1933, dão o que pensar em muitos sentidos” (GRONDIN, 2000, p. 229); contudo, é inegável a presença da filosofia de Heidegger nos textos de Gadamer, assim como é impossível pretender compreender a hermenêutica filosófica gadameriana desvencilhada das influências do seu orientador de 
doutorado. Prova inconteste disso estampa-se na quantidade de referências a Heidegger na biografia de Gadamer escrita por Jean Grondin (2000), onde nenhum outro filósofo é tantas vezes citado quanto ele. Outra marca da hermenêutica gadameriana lança suas raízes no curso ministrado por Heidegger, em 1923, sobre Ética a Nicômaco, quando "surpreendeu a seu auditório ao identificar a virtude prática, a phrônesis, com a consciência moral que nos chama a voltarmo-nos sobre nós mesmos" (GRONDIN, 2000, p. 148); conceito que transpassa a hermenêutica filosófica de Gadamer.

Além de Heidegger ter se comprometido com o partido nazista e confessado antissemitismo, ele desferiu críticas contundentes aos seus discípulos por não o terem acompanhado em suas convicções políticas e terem, inclusive, estranhado e o questionado sobre isso. Na biografia de Gadamer as seguintes passagens retratam isso: "para Heidegger, os seus discípulos que em 1933 não o haviam seguido politicamente eram 'meninos burgueses fracos, incapazes de pensar com radicalismo"' (GRONDIN, 2000, p. 230); e noutra passagem:

os alunos e amigos de Heidegger em Marburgo estavam realmente surpreendidos com sua cegueira. Assim, nenhum dos seus discípulos importantes o seguiu, pois Heidegger, aluno de Husserl, se havia posto totalmente no ridículo ao tomar partido por um movimento antissemita. Heidegger, por sua parte, estava amargurado por essa falta de seguimento por parte de seus titubeantes, liberais e indecisos discípulos (GRONDIN, 2000, p. 210-212).

O fato é que "o isolamento e a humilhação que resultaram para Heidegger da atitude assumida por eles foram, em parte, a razão de sua renúncia ao reitorado, em abril de 1934", momento em que "o caráter terrorista do governo de Hitler, até o momento escondido atrás de uma legalidade democrática, se tornou indiscutível para todos" (GRONDIN, 2000, p. 210-212).

Gadamer se afastou de Heidegger e não o viu entre 1933 e 1938; porém, preocupado com o rechaço e o desprezo desferido contra ele, organizou, em 1949, a publicação de um livro por ocasião dos seus 60 anos. Empreendimento delicado Jaspers, por exemplo, se recusou a contribuir com um texto - pois se encontrava, então, proscrito de muitos círculos. Gadamer foi condescendente pois sabia que, já em meados dos anos 30, Heidegger havia compreendido seu erro político (GRONDIN, 2000, p. 358-359) e, assim, posteriormente ajudou a tirá-lo do 
ostracismo, "impondo sua eleição como membro da Academia das Ciências de Heidelberg" e recebendo-o em Heidelberg, alojando-o com frequência na sua casa e organizando "pequenos seminários" (GRONDIN, 2000, p. 359) ${ }^{4}$ ministrados por Heidegger. Se, por um lado, podemos dizer que Heidegger pende para uma postura, por assim dizer, mais monológico-analítica, Gadamer pautou sua conduta e sua produção filosófica pelo exercício dialético-dialógico na esteira da herança socráticoplatônica ${ }^{5}$. Talvez possamos dizer que, enquanto Heidegger ditava sua forma de pensar, Gadamer a tecia mediante a prática dialógica e confronto constante considerando o direito e os argumentos dos outros. Foi essa postura de abertura, de disposição ao diálogo, de amor pela verdade, que o levou a estender a mão para Heidegger e a continuar se apropriando da sua obra, apesar do seu equívoco ideológico-político.

\subsection{Por que ainda ler Heidegger?!}

Se, por um longo período de tempo, a efetiva adesão heideggeriana ao nazismo fora colocada em dúvida por parte da comunidade filosófica, a publicação dos Cadernos Pretos expõe de forma inegável uma marca antissemita, tanto na vida como no pensamento do filósofo alemão. Contudo, estes mesmos comentadores argumentam que o antissemitismo de Heidegger não coincidiu com o antissemitismo do partido nacional-socialista. Além disso, é preciso notar que o comprometimento com o nazismo não foi uma consequência necessária do seu pensamento, ou seja, a filosofia heideggeriana não pode ser considerada dependente das suas convicções ideológicas, na medida em que abre possibilidades para o pensamento que não se encontram limitadas à ideologia nazista.

\footnotetext{
${ }^{4}$ Sobre isto ainda, Grondin (2000, p. 360) comentou: "Porém salvo raras exceções, não logrou entusiasmar a seus estudantes por Heidegger. O que ele oferecia não eram seminários, mas monólogos, aos quais não estavam acostumados desde o ensinamento de Gadamer".

${ }^{5}$ Sobre as proximidades e distanciamentos relativos à filosofia de Heidegger e de Gadamer, ver ROHDEN, L. "Hermenêutica filosófica: entre Heidegger e Gadamer". Natureza Humana, v. 14, p. 14-36, 2012.
} 
Em que pese o condenável comprometimento político de Heidegger, com o qual não compactuamos, seu pensamento fornece contribuições para a filosofia moral. Ao evidenciar a analítica existencial como uma instância prévia à moralidade, Heidegger chama a atenção para um mundo pré-reflexivo, condição de possibilidade para a própria ética, e que não pôde ser observado pelas teorias tradicionais da ética filosófica em razão dos limites da própria metafísica. Ao mostrar esta instância prévia e suas implicações para a reflexão filosófica acerca dos temas éticos, Heidegger oferece elementos para um conceito de ética mais alinhado à condição do Dasein enquanto ser-no-mundo.

Seguimos o mote "amigo da verdade mais do que de Platão" no sentido aqui, de que, na prática filosófica, não lemos obras apenas porque nos parecem simpáticas ou que vêm de encontro ao nosso modo de pensar e proceder. Assim como lemos ou não lemos, necessariamente, $\mathrm{x}$ ou y porque é de um ou outro partido, porque é amigo ou inimigo, a adesão ou a rejeição ou a condenação da filosofia de Heidegger não se justifica, apenas, pelo critério da simpatia - embora esta participe, decisivamente, tanto na construção quanto na interpretação de uma obra —, mas pela procura da verdade com e, para além da amizade, se for o caso.

Precisamos levar em conta e lidar com o pressuposto segundo o qual a compreensão do texto filosófico se erige sobre a lógica do pertencimento e do distanciamento. De uma parte, o escrito encontra-se inserido num contexto, pertence a um espírito do tempo do qual o autor, ao escrever, não está imune ou consegue, mesmo se esforçando, permanecer ileso; de outra parte, sua interpretação estriba-se sobre o esforço de se debruçar sobre o texto exercitando a epoché a fim de se ater à coisa mesma, isto é, ao que está em questão escrito nele.

Gadamer, embora fizesse parte daquele tempo, conseguiu se desvencilhar do espírito antissemita e se apropriou da filosofia de Heidegger, distanciando-se da sua postura relativa à filiação partidária e às suas convicções ideológicas. Com um olhar hermenêutico de pertencimento e de distanciamento, que configura uma circularidade virtuosa, concluímos que as confissões dos Cadernos Pretos minimizaram o brilho, mas não a potência filosófica da obra de Heidegger. O reconhecimento do seu erro político e esclarecimento de que era um crítico contumaz de um modo de agir instrumental — que ele, lastimavelmente, identificou sendo próprio da postura 
dos judeus — indicam que sua obra não tem pretensão de fazer apologia do nazismo ou do antissemitismo.

Nesse sentido, alinhamo-nos a André Duarte e Peter Trawny na interpretação de que o conteúdo das passagens antissemitas extraídas da obra heideggeriana de modo algum configura apologia ao nazismo ou defesa do extermínio dos judeus. Observa Trawny (2015, p. 19) que "as declarações de Heidegger sobre os judeus não podem ser conectadas com Auschwitz", enquanto Duarte (2015, p. 32) vai mais longe ao sustentar que

\begin{abstract}
por certo não encontraremos nos Cadernos Pretos nenhuma afirmação na qual Heidegger defenda o extermínio do povo judeu ou de outros povos, visto que seu antissemitismo filosófico nada tem que ver com o genocídio e, portanto, não se encontra 'enredado com Auschwitz' ou com concepções raciais de natureza estritamente biológica.
\end{abstract}

Convém fazermos o esforço para distinguirmos - no trato com nossos amigos, parentes ou parceiros de profissão — o quanto for possível, a obra do seu criador. Nesse sentido, vem ao nosso encontro a seguinte afirmação de Ricoeur (1989, p. 143):

às vezes, gosto de dizer que ler um livro é considerar o seu autor como já morto e o livro como póstumo. De fato, é quando o autor está morto que a relação com o livro se torna completa e, de certo modo, intacta; o autor já não pode responder, resta apenas ler a sua obra.

O texto, uma vez escrito, ganha vida própria, conquista sua autonomia e, de certa forma, se torna independente do seu criador; assim como um filho que sempre será relativo ao seu pai, ele não será apenas mais seu filho ao se tornar independente e se tornar pai. O filho, analogamente ao texto escrito, em sua autonomia, não poderá mais ser julgado única e exclusivamente em função da sua filiação. No caso do escrito de Heidegger, podemos interpretá-lo desvinculado da opção política e ideológica do seu criador, assim como devemos rechaçá-lo caso viesse justificar o nazismo ou o antissemitismo. Os textos têm vida própria e se tornam, assim, passíveis de serem interpretados, em grande medida, independentemente da ideologia ou das intenções do seu criador. No caso de Heidegger, conforme já destacamos anteriormente, estamos de acordo que não escreveu com intenção apologética de defender nem o nazismo nem o antissemitismo característico no partido nacional-socialista, embora algumas sentenças 
nos Cadernos expressem, de forma inegável, um certo antissemitismo culturalmente disseminado na Alemanha da época.

Com relação aos textos de Heidegger, só nos resta interpretar pois seu criador já não pode mais responder por eles —, e a tarefa que se nos impõe é fazer isso de forma honesta e responsável (GEORGE, 2014). Assim como não é honesto, nem justo, nem responsável, identificar Übermensch de Nietzsche com a criação do mito do ariano do terceiro reich, também pode ser posto na conta da desonestidade intelectual para com a obra de Heidegger, ignorá-lo ou aderir cegamente ou descartá-la do baralho filosófico por causa do seu envolvimento político e posição antissemítica. A filosofia hermenêutica erige-se sobre a tarefa de compreender os textos de modo responsável, atenta ao seu significado e ao sentido (ROHDEN, 2004), e não à ideologia dos seus criadores.

A leitura de Heidegger ainda hoje se justifica à medida que possibilita instaurar novos sentidos. Um texto filosófico tem tanto mais valor e vigor quanto mais permite e possibilita instaurar sentidos, isto é, (a) alimenta nossa imaginação, nosso desejo investigativo; (b) faculta iluminar, ampliar e fundir nossos horizontes de compreensão; (c) dá o que pensar e nos ajuda a pensar, discernir, ouvir e ver melhor; (d) contribui para orientar nossa ação no mundo; (e) e, enfim, dá razões e motivos para ser e viver de modo autêntico. O existir autêntico possibilita uma participação mais rica e completa no contexto público, nos tornando mais responsáveis por nossas decisões e pelo que fazemos de nós mesmos. Compreender implica em romper hábitos, dogmas e propensões totalitárias que, por sua vez, nos permite tornar mais nós mesmos sob a égide da liberdade, da justiça, do respeito à pluralidade e aos direitos humanos nos moldes de uma ética originária, de matiz heideggeriana, conforme sugere Dennis Schmidt (2008). ${ }^{6}$

\footnotetext{
6 "The argument that I want to make is that the philosophical hermeneutics we find formulated in Gadamer's work is fundamentally - not accidentally or subsequently, but fundamentally - concerned with the task of thinking that which Heidegger referred to as 'an original ethics" (SCHMIDT, 2008, p. 36).
} 


\section{Conclusões}

O filósofo e sua filosofia são filhos do seu tempo, mas também tentam ir além do espírito do seu tempo. As filosofias são tecidas na corrente linguística do seu tempo, mas o filósofo é capaz de emergir de suas águas e, - como o salmão que salta da torrente onde se encontra - com horizonte alargado, procura ver o todo. No caso, o que importa, no trato com os textos de Heidegger, é sua rica história efeitual (Wirkungsgeschichte) atestada pela apropriação de filósofos do mundo todo. E quanto à extensão da influência do antissemitismo de Heidegger para a sua filosofia, parece ainda cedo para que uma resposta definitiva seja apresentada. Depurar a Gesamtausgabe, para dela retirar o que estiver contaminado pela ideologia antissemita, é uma tarefa a realizar, e está lançada à comunidade filosófica como um todo.

Com a publicação dos Cadernos Pretos, contudo, fica evidente que as sentenças antissemitas não representam, necessariamente, um compromisso filosófico de Heidegger com a ideologia nacional-socialista. Ao mesmo tempo em que Heidegger condena a atitude do nacional-socialismo em sua invocação ritualística da "comunidade", o antissemitismo heideggeriano nada tem que ver com genocídio ou com concepções raciais de natureza biológica.

Empreender o esforço para distinguir a obra do seu criador é a tarefa que se impõe a toda tentativa honesta e responsável de interpretação. Uma vez escrito, o texto ganha autonomia, se torna independente do seu criador e sua apropriação é justificável à medida que estimula nossa imaginação, fomenta nosso espírito criativo, alimenta nossa curiosidade e desejo de ser e de saber. Heidegger permanece um filósofo que merece ser lido e seus textos interpretados, uma vez que sua contribuição para a filosofia - na qual podemos incluir suas contribuições para a filosofia moral -, seja balizada e cotejada por intérpretes especializados, não pode ser desprezada puramente em razão da sua indesculpável posição política e ideológica. O que importa, pois, conforme exemplo da prática dialógica de Gadamer, é mantermos a disposição ao diálogo sobre todos os temas e problemas que nos dizem respeito, afinal, de contas, mau filósofo é aquele que pretende ter a última palavra sobre determinado assunto. 


\section{Referências}

DUARTE, A. Heidegger, a política e o antissemitismo: reflexões a partir do livro de Peter Trawny. O Que nos Faz Pensar, n. 36, p. 27-51, 2015.

ESCUDERO, J. A. Heidegger's Black Notebooks and the question of anti-semitism. Gatherings. The Heidegger Circle Annual, v. 5, p. 21-49, 2015.

FARIN, I. The Black Notebooks in their historical and political context. In: Reading Heidegger's Black Notebooks 1931-1941. Cambridge: The MIT Press, 2016. p. 289-321.

FAYE, E. Heidegger: a introdução do nazismo da filosofia em torno dos seminários de 19331935. Trad. Paulo Rouanet. São Paulo: É Realizações, 2015.

FRIED, G. The king is dead: Martin Heidegger after the Black Notebooks. In: Reading Heidegger's Black Notebooks 1931-1941. Cambridge: The MIT Press, 2016. p. 45-57.

GEORGE, T. "Responsibility to Understand”. In: HEIDEN, G. J. (ed.). Phenomenological Perspectives on Plurality. Leiden: Brill Publishing, 2014.

GRONDIN, J. Hans-Georg Gadamer. Uma biografia. Herder: Barcelona, 2000.

HATAB, L. J. Ethics and finitude: Heideggerian contributions to moral philosophy. Maryland: Rowman and Littlefield Publishers, 2000.

HEIDEGGER, M. Sein und Zeit. 19. ed. Tübingen: Max Niemeyer Verlag, 2006.

HEIDEGGER, M. Überlegungen II-VI (Schwarze Hefte 1931-1938). Frankfurt am Main: Vittorio Klostermann, 2014a.

HEIDEGGER, M. Überlegungen VII-XI (Schwarze Hefte 1938-1939). Frankfurt am Main: Vittorio Klostermann, 2014b.

HEIDEGGER, M. Überlegungen XII-XV (Schwarze Hefte 1939-1941). Frankfurt am Main: Vittorio Klostermann, 2014c.

MALPAS, J. On the philosophical reading of Heidegger: situating the Black Notebooks. In: Reading Heidegger's Black Notebooks 1931-1941. Cambridge: The MIT Press, 2016. p. 3-22.

RALON, L. 'Interview with Günter Figal'. Figure/Ground. August $18^{\text {th }}, 2015$. Disponível em: http://figureground.org/interview-with-gunter-figal/. Acesso em: 23 out. de 2019.

RICOEUR, P. Do texto à ação: ensaios de hermenêutica II. Trad. Alcino Cartaxo e Maria José Sarabando. Porto: RÉS-Editora, 1989.

ROHDEN, L. “Sobre o Sentido”. Veritas, Porto Alegre, v. 50, p. 293-303, 2004.

ROHDEN, L. "Hermenêutica filosófica: entre Heidegger e Gadamer". Natureza Humana, v. 14, p. 14-36, 2012. 
SAFRANSKI, R. Heidegger, um filósofo da Alemanha entre o bem e o mal. Trad. Lya Luft. São Paulo: Geração Editorial, 2005.

SCHMIDT, D." Hermeneutics as Original Ethics". In: SCHMIDT, D. Difficulties of Ethical Life. New York: Fordham University Press, 2008. p. 35-50.

SHEEHAN, T. Emmanuel Faye: the introduction of fraud in philosophy. Philosophy Today, v. 59, n. 3, p. 367-400, 2015.

TRAWNY, P. Heidegger e o mito da conspiração judaica mundial. Trad. Soraya Guimarães Hoepfner. Rio de Janeiro: Mauad X, 2015.

RECEBIDO: $25 / 03 / 2020$

APROVADO: $19 / 06 / 2020$

RECEIVED: 03/25/2020

APPROVED: 06/19/2020 